\begin{tabular}{|c|c|c|}
\hline 150 (150) & $\begin{array}{c}\text { Bulletin of Pharmaceutical Sciences } \\
\text { Assiut University }\end{array}$ & 6 \\
\hline 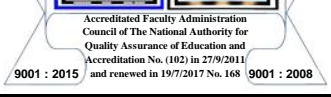 & $\begin{array}{c}\text { Website: http://bpsa.journals.ekb.eg/ } \\
\text { e-mail: bullpharm@aun.edu.eg }\end{array}$ & $\begin{array}{l}\text { BULL, PHARM. SCI. } \\
\text { Assiut Univ. }\end{array}$ \\
\hline
\end{tabular}

\title{
TOTAL FLAVONOID CONTENT, MICROSCOPIC AND MICROBIAL EVALUATION OF SYRIAN GINKGO BILOBA PRODUCTS
}

\author{
Nawar Ahmad ${ }^{1 *}$, Hani Salim ${ }^{2}$ and Ramez Rustom ${ }^{3}$ \\ ${ }^{1}$ Department of Drug Quality Control and Pharmaceutical Chemistry, Faculty of Pharmacy, Al-Baath \\ University, Homs, Syria \\ ${ }^{2}$ Department of Drug Quality Control and Pharmaceutical Chemistry (Drug synthesis), Faculty of \\ Pharmacy, Al-Baath University, Homs, Syria \\ ${ }^{3}$ Department of Clinical Pharmacology, Faculty of Medicine, Al-Baath University, Homs, Syria
}

\begin{abstract}
Ginkgo Biloba $(G B)$ is a widely used finished herbal product. Due to its natural source there is no demand to evaluate its quality before marketing. Although GB products have shown promising potential with the efficacy, many of these products remain untested. The Current work aims to evaluate some quality parameter of GB finished products like total flavonoid content (TFC), microscopic, Loss On Drying (LOD) and microbial tests in comparison with GB crude plant. The TFC ranged from (22.86 to $78.74 \mathrm{mg} / \mathrm{g}$ ). Microscopic findings revealed the presence of large amounts of starch grains in product A. Furthermore, most of the products were heavily contaminated with bacteria and fungi. As bacterial colony counts ranged from $\left(10^{3}\right.$ to $\left.7.5^{\times} 10^{5} \mathrm{CFU} / \mathrm{g}\right)$ and from $\left(1.7^{\times} \times 10^{3}\right.$ to $\left.0.75^{\times} 10^{7} \mathrm{CFU} / \mathrm{g}\right)$ for fungal colony counts. Most of the products exceeded the reference limits for LOD. thus may pose a threat to consumer's health.
\end{abstract}

\section{INTRODUCTION}

The use of herbal products (HP) is continually expanding worldwide with many people now resorting to these products for treatment of various diseases. Yet, there is insufficient information about its safety, purity and effectiveness, which raise a great concern about the quality and safety of these products ${ }^{1}$. Generally, it is believed that the risk associated with herbal drugs is very low, but several reports on serious effects indicate the need for development of safety profiles and stringent quality control systems for authentication and standardization of $\mathrm{HP}^{2}$. Ginkgo folium (Ginkgoaceae) is a very important medicinal herb, as numerous studies reported GB ability to enhance peripheral circulation and slow the progression of Alzheimer's disease ${ }^{3}$. In fact, the chemical composition of $\mathrm{GB}$ is quite complicated, as flavonoids constitute are the largest groups of bioactive substances isolated from $\mathrm{GB}^{4}$. Moreover, the content of flavonoids is considered as an important index for evaluating GB products quality ${ }^{5}$. A variety of analytical methods can be used to quantify these compounds, however UV/Vis spectrophotometric determination became one of the most widely used methods for quantification of total flavonoids due to its simplicity and low cost of implementation. This approach becomes more critical due to the high cost or absence of reference substance needed for determination of individual flavonoids ${ }^{6}$. On the other hand, the microscopic $\&$ microbial evaluation are essential steps in verifying HP purity, and safety. The current study aims to evaluate the total flavonoid content (TFC), Microscopic, Microbial and LOD testes of GB products, as they are the most important parameters for quality evaluation of $\mathrm{HP}^{7}$. After all adhering GMP to all production stages is very important to obtain high quality products with no harmful effects. 


\section{MATERIAL AND METHODS}

\section{Chemical and Equipment}

Automatic mill, Ethanol Solution 70\%, aluminum chloride $(10 \% \mathrm{w} / \mathrm{v})$, potassium acetate $(1 \mathrm{M})$, distilled water, quercetin standard (Aldrich Chemical), Spectrophotometer (Shimadzue), chloral hydrate solution $60 \%$, iodine solution $1 \%$, nutrient and MacConkey agar medium (HiMedie-India), Sabouraud Dextrose Agar medium (SDA) (Accumix-India), Autoclave (Dampfsterilsator Germany - Variokla), Incubator (Carbolite - UK), Micros Optical Microscope (Austria, Precisa-XB220), Switzerland. All solvents were of analytical grade.

\section{Samples}

Three different batches of three GB products $(\mathrm{A}, \mathrm{B}$ and $\mathrm{C})$ were purchased from local Syrian pharmacies. GB crude plant was kindly gifted from Syrian Pharmaceutical Industries (Homs, Syria). The crude plant was grinded into powder using the automatic mill. $\mathrm{A}$ and $\mathrm{B}$ products were capsules with dried leaves powders, while $\mathrm{C}$ products were capsules with dried leaves extract. The batches were coded 1, 2, 3 respectively.

\section{Estimation of Total Flavonoid Content (TFC)}

The total flavonoid content of GB samples were determined using the aluminum chloride assay. Fifty $\mathrm{g}$ of powdered samples was extracted by reflux using $70 \%$ ethanol as the solvent for $2 \mathrm{hrs}$. and repeated 3 times. The extracts then evaporated using a vacuum rotatory evaporator, and then dried in water bath on $50^{\circ} \mathrm{C}$. Briefly, to $0.5 \mathrm{~mL}$ of sample, ethanolic solution of aluminum chloride $(10 \%$ w/v), potassium acetate $(0.1 \mathrm{~mL}$ of $1 \mathrm{M})$ and distilled water $(4.3 \mathrm{~mL})$ were added. After 15 min of incubation the mixture turns to pink whose absorbance was measured at $510 \mathrm{~nm}$ using a spectrophotometer. Obtained results were expressed in $\mathrm{mg} / \mathrm{g}$ quercetin equivalents $^{4 \& 8}$.

\section{Microscopic Evaluation Method}

Samples were tested by adding few drops of chloral hydrate solution $60 \%$ and the powders was studied using light microscope with 10 and 40 lenses. An iodine solution was used to detect the presence of starch grains in the studied samples. GB crude plant was used as comparative material.

\section{Loss on Drying Test (LOD)}

It was conducted by taking $1 \mathrm{~g}$ of product A, B and GB crude plant, followed by heating in an oven at $105^{\circ} \mathrm{C}$ for two hrs. The percentage of LOD is calculated by the equation":

The percentage of $\mathrm{LOD}=$ Weight of the material before drying - Weight of the material after drying/Weight of the material after drying $\times 100$

\section{Microbial Evaluation Method}

The samples were investigated for the presence of bacterial and fungal contamination by using the methods described in USP 41NF36 with some modifications (10). All medium for microbial analysis was prepared according to manufacturer's guidelines. The culture tubes were prepared using distilled water, then it was diluted in a sufficient ratio to obtain an aqueous suspension that could be implanted and counted (10/100). The preservative efficacy was canceled by dilution to $100 \mathrm{ml}$. The spread plate method was used and $0.1 \mathrm{ml}$ of each tube was implanted on the medium mentioned above then were incubated at $37{ }^{\circ} \mathrm{C}$ for $48 \mathrm{hrs}$. including the negative control for nutrient agar and MacConkey agar. SDA samples were incubated at $25{ }^{\circ} \mathrm{C}$ for 7 days. Results were reported as the counts of colony forming Units (CFU) per each gram or $\mathrm{ml}$. Three samples of each tube were counted for CFU and the mean was calculated. At the end of incubation period, pathogenic bacterial isolates were preliminary characterized by colony morphology, Gram staining, and biochemical tests (catalase production) ${ }^{9}$.

\section{RESULTS AND DISCUSSION}

\section{Estimation of Total Flavonoid Content (TFC)}

The flavonoids content was calculated using the following linear equation based on the quercetin calibration curve: $\mathrm{Y}=0.0066 \mathrm{C}+$ $0.1303, \mathrm{R}^{2}=0.9978$, where $\mathrm{Y}$ is the absorbance and $\mathrm{C}$ is the flavonoids content in $\mathrm{mglg}$. The standard curve of quercetin clarified in Fig.1, as the results of TFC included in table 1. 
Table 1: Total Flavonoid Content (TFC) in GB samples

\begin{tabular}{|c|c|c|c|c|c|c|c||c||c|}
\hline sample & Crude plant & A1 & A2 & A3 & B1 & B3 & C1 & C2 & C3 \\
\hline \hline TFC $\mathrm{mg} / \mathrm{g}$ & 23.48 & 58.89 & 78.74 & 43.43 & 27.98 & 26.01 & 22.86 & 24.43 & 23.28 \\
\hline
\end{tabular}

The TFC in the studied GB samples ranged from 22.86 to $78.74 \mathrm{mg} / \mathrm{g}$, as the lowest value was found in product $\mathrm{C} 1(22.86 \mathrm{mg} / \mathrm{g})$, while the highest value was found in product A2 $(78.74 \mathrm{mg} / \mathrm{g})$. Moreover, TFC values vary between the batches of each product. It was observed that TFC values in all products were higher than TFC values in GB crude plant. This matches with the results of E. Pereira, as the TFC in commercial GB products in E. Pereira study were higher than TFC in the crude plant $^{11}$.

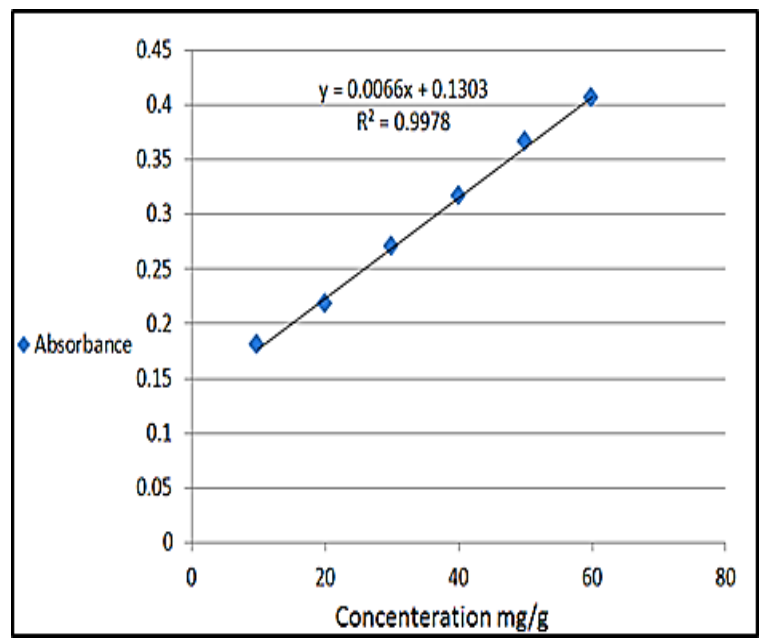

Fig. 1: Standard calibration curve of quercetin

Also, it was observed that the TFC in Capsules with GB dried leaves powders (products A and B) were higher than Capsules with GB dried extracts powders (product $\mathrm{C}$ ). This also matches with the results of E. Pereira study as TFC values were higher in Capsules with the GB dried leaves powders ${ }^{11}$. On one hand, one of the extraction steps is the plant exposure to high temperatures thus, flavonoids chemical structure become unstable and cause decline in its content in the plant samples ${ }^{11}$. On the other hand, the climatic and geographical conditions, environmental factors, soil as well as the age of the plant ${ }^{13-15}$, in addition, the extraction and drying methods play a major role in the TFC variation in samples ${ }^{16 \& 17}$. Moreover, the different colors of GB leaves can affect TFC, as it was reported $t$ hat the yellow leaves had the highest TFC, while the lowest content exhibited on leaves in green color. This indicated GB leaf in pure green color is not suitable for harvesting due to its low TFC. Furthermore, total flavonoids concentrations change rapidly in GB leaves in green-yellowish and yellow colors. Therefore determination of total flavonoids content in GB leaf could be used to decide the harvest time and estimate the quality of $\mathrm{GB}^{4}$.

\section{Microscopic Evaluation}

This test was conducted on products (A, B) and GB crude plant which is used as a comparative material. The results of microscopic tests were included in fig.2. The crude plant leaves powder was greenyellowish, while the products powders color ranged from green, yellow to green-yellowish. As the product $\mathrm{A}$ and $\mathrm{B}$ powders colors varied in their different batches. In fact, the leaves color may differ depending on season, harvesting, drying method and many other factors. The microscopic evaluation showed characteristic microscopic features of GB leaf lamina, which are fragment of upper and lower epidermal cells in surface view that is similar in shape, but lower epidermis is characterized by the presence of sunken anomocytic stomata $^{18}$. Also, xylem vessels with annular thicknesses appeared in all samples. Moreover, cluster crystal of calcium oxalate is one of the most important distinguishing elements of GB, where different sizes of these crystals were observed, and it reflected the leaf age and the chemical composition or quality of the leaf. The presence of particles with maximum sizes suggested that the leaves are of old age. Furthermore, starch grains were abundant particularly in product A2, it was ribbed with a central helium and presented in large amounts that impeded the microscopic detection to some extent, especially in product A3 (Fig.2). Starch grains were not observed in all batches of product B. In fact, some references reported that starch grains may be present in small amounts, but they do not present in these large quantities as it was observed in product A3. So, 
the presence of this amounts of starch grains may be due to mixing GB powders with starch powders. On the other hand, aromatic cavities and secretory canals were also observed in frontal view, which are large and full of yellowish-brown content. Although some references do not classify it as a characteristic diagnostic component of GB leaves, but it was clearly observed in all samples. This findings are corresponding to GB comparative crude plant, references and matches with $\mathrm{S}$. Ion study of GB microscopic features ${ }^{18-19}$.

\section{Loss on Drying (LOD) Results}

The LOD results is included in Table 2. It was observed that LOD average values were higher in crude plant $(17.4 \%)$ than the finished products. As product $\mathrm{A}$ had the lowest LOD average value of $(11.33 \%)$. Moreover, all average values of the samples exceeded the permissible limits for LOD which indicates a high moisture content. As the preserving and drying methods can affect LOD results ${ }^{20}$.

\section{Microbial Evaluation}

The results of Total Aerobic Count (TAC) on Nutrient Agar are included in Table 3 and The results of Total yeasts and molds count (TYMC) on SDA are included in Table 4. Results indicated that $75 \%$ of the samples were bacterial contaminated. Furthermore, it was observed that product A2 and A3 were within the acceptable limits ${ }^{10}$, while all batches of product $\mathrm{B}$ exceeded the permissible limits. This results matches with the results of Ratajczak study ${ }^{21}$. There was no bacterial growth on all batches of Product $\mathrm{C}$. The absence of bacterial growth in all batches of product $\mathrm{C}$ may be due to the fact that this product is a dry extract, and extraction is a stringent way of treatment thus kill all types of living cells, including spores ${ }^{22}$.

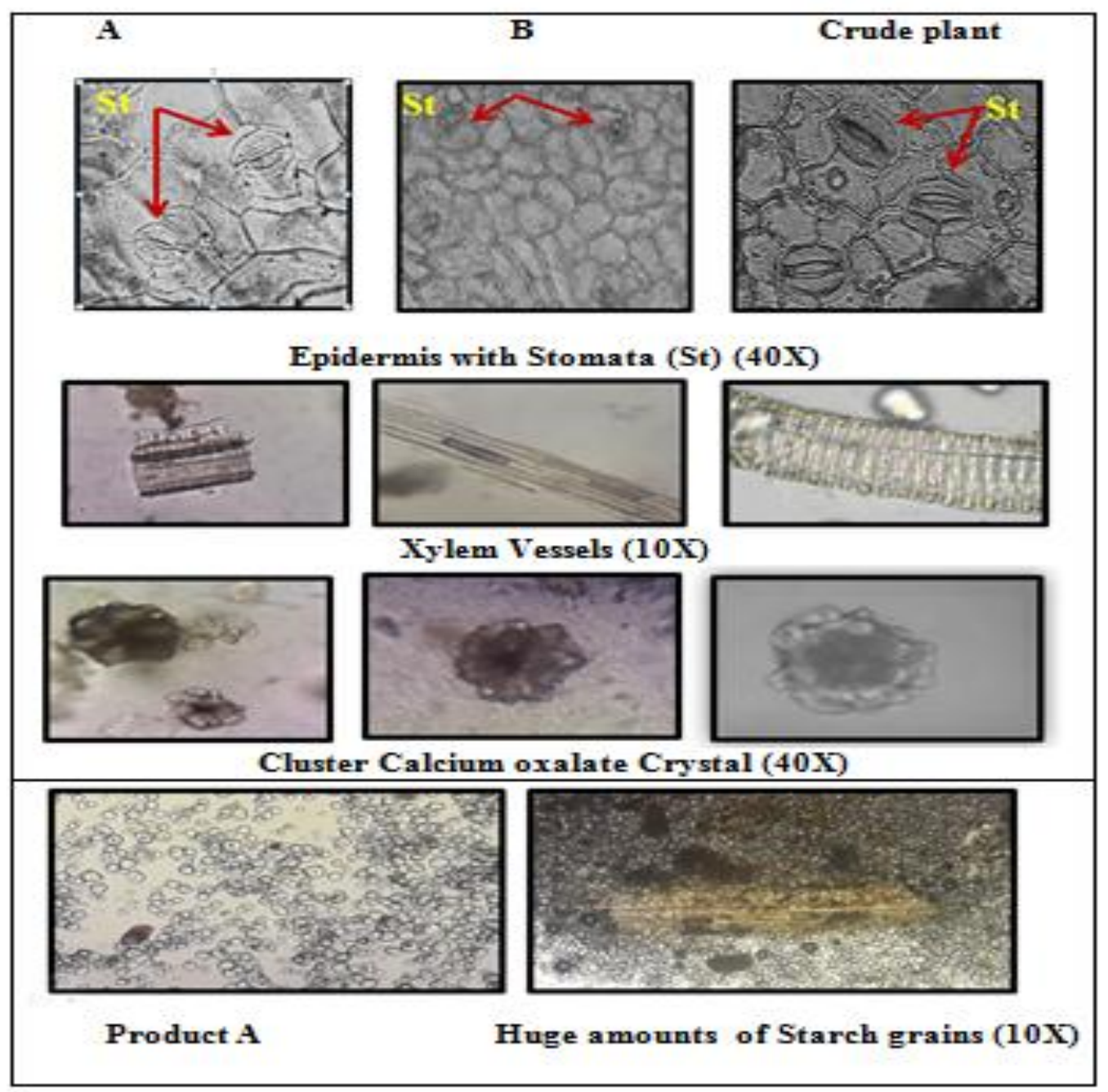

Fig. 2 : The microscopic results of Ginkgo Biloba samples 
Table 2: The results of Loss On Drying test (LOD)

\begin{tabular}{|c|c||c||c|}
\hline A \% & B \% & Ginkgo leaf \% & Reference limits (10) \\
\hline \hline 11.33 & 13.46 & 17.4 & NMT 11\% \\
\hline
\end{tabular}

Table 3: The results of Total Aerobic Count (TAC) on Nutrient

\begin{tabular}{|c||c|c|c|c|c||}
\hline Product & Type & Batch No.1 & Batch No.2 & Batch No.3 & $\begin{array}{c}\text { Reference limits } \\
(\mathbf{1 0})^{\mathbf{1}} \text { CFU/g }\end{array}$ \\
\hline \hline A & $\begin{array}{l}\text { Dried leaves } \\
\text { Powder }\end{array}$ & $1.5 \times 10^{6}$ & $1.9 \times 10^{3}$ & $1.7 \times 10^{3}$ & ${ }^{3}$ NMT $10^{5}$ \\
\hline B & $\begin{array}{l}\text { Dried leaves } \\
\text { Powder }\end{array}$ & $1.3 \times 10^{6}$ & $1.7 \times 10^{6}$ & $1.6 \times 10^{6}$ & NMT $10^{5}$ \\
\hline $\mathbf{C}$ & $\begin{array}{l}\text { Dried leaves } \\
\text { extract }\end{array}$ & -- & -- & -- & NMT $10^{4}$ \\
\hline $\begin{array}{c}\text { Crude } \\
\text { plant }\end{array}$ & $\begin{array}{l}\text { Dried leaves } \\
\text { Powder }\end{array}$ & $0.7 \times 10^{7}$ & $0.75 \times 10^{7}$ & $0.71 \times 10^{7}$ & NMT $10^{5}$ \\
\hline
\end{tabular}

NMT: Not more than

${ }^{1}$ According to USP41-NF36 (21), ${ }^{2}$ Colony forming units per gram, ${ }^{3}$ Not more than. TYMC:

Total yeasts \& molds count.

Table 4: The results of Total yeasts and molds count (TYMC) on SDA

\begin{tabular}{|c||c|c||c|c|c||}
\hline Product & \multicolumn{1}{|c|}{ Type } & Batch No.1 & Batch No.2 & Batch No.3 & $\begin{array}{c}\text { Reference limits } \\
(\mathbf{1 0})^{\mathbf{1}} \mathbf{C F U} / \mathbf{g}^{\mathbf{2}}\end{array}$ \\
\hline $\mathbf{A}$ & $\begin{array}{l}\text { Dried leaves } \\
\text { Powder }\end{array}$ & $1.2 \times 10^{3}$ & $3.0 \times 10^{3}$ & $10^{3}$ & NMT $10^{3}$ \\
\hline \hline $\mathbf{C}$ & $\begin{array}{l}\text { Dried leaves } \\
\text { Powder }\end{array}$ & $1.0 \times 10^{4}$ & $1.1 \times 10^{4}$ & $1.05 \times 10^{4}$ & NMT $10^{3}$ \\
\hline \hline $\begin{array}{l}\text { Crude } \\
\text { plant }\end{array}$ & $\begin{array}{l}\text { Dried leaves } \\
\text { extract }\end{array}$ & $1.1 \times 10^{3}$ & $1.7 \times 10^{3}$ & $1.3 \times 10^{3}$ & NMT $10^{3}$ \\
\hline \hline
\end{tabular}

${ }^{1}$ According to USP41-NF36 (21), ${ }^{2}$ Colony forming units per gram, ${ }^{3}$ Not more than. TYMC:

Total yeasts \& molds count 
Crude plant was more contaminated than finished herbal products (A, B) due to treatment processes which reduce microbial load. This is corresponding to the results of Santos $s^{2}{ }^{23}$. In fact, microbial tests often reveal the presence of bacilli type bacteria and its presence is associated with food borne diseases, moreover, this type of bacilli is dangerous because of its ability to form internal resistant spore which could live on products in a dormant state for a long time and couldn't be easily removed. No growth was observed on McConkey medium of any of the studied samples which may indicate the sample were free of negative gram bacteria, and that corresponds to A. Okunlola study ${ }^{24}$. The positive Catalase test indicates the presence of Staphylococcus aureus colonies in product A. Moreover, all samples were heavily contaminated with fungi, and mostly of Aspergillus Flavus, which is considered a great hazard to health due to Aspergillus toxic spores which may be formed, as in a study of Tournas $^{25}$. As large number of fungi colonies indicates continuous spoilage of the product with negative effects on its quality and pharmacological properties ${ }^{26}$. Storage in poorly ventilated place, for example, may lead to high temperature and increased moisture, moreover dried plant materials absorb moisture easily, which leads to the increase in microbial load of products $^{27}$.

The LOD results showed a very strong correlation with products microbial load using the Pearson, as Pearson coefficient was 0.9675 for correlation between LOD and bacterial growth, while it was 0.9360 for correlation between LOD and fungal growth, which indicated that bacterial and fungal growth increases as moisture content of products increases.

\section{Conclusion}

The use of herbal products has increased rapidly with no applying of quality control in the same acceleration of products spread. In this research, the TFC, microscopic, LOD and microbial tests of Syrian GB products were conducted. Flavonoids are key candidate compounds for evaluating the quality of GB products. The results confirmed the presence of GB leaf which is stated on the product label. Large amounts of starch grains were observed in some products. Moreover, most of products were highly contaminated with bacteria and fungi. Consequently, these products may affect patients health badly as well as affect product stability. However, finished products were generally less contaminated than crude plant. The elevated levels of contamination indicate inadequate storage procedures, failure to follow good hygienic practices and failure to adherence to GMP. The WHO recommends to store fresh medicinal plants at low temperatures, and therefore farmers should be trained for GMP, planting practices, Good agriculture and Good collection practice (GACP) and appropriate storage. All countries should make efforts to build consumers trust in herbal products by ensuring their safety and following GMP regardless of where it is manufactured and purchased.

\section{Acknowledgments}

The authors are thankful to The Pharmacy Institute, Al-Baath University for using laboratory equipment.

\section{REFERENCES}

1. F. Shaikh, A. Salunkhe and S. Kadam, "An Outlook Towards the Microbial Quality of Marketed Herbal Medicinal Formulations", Am J PharmTech Res, 9(02),171 - 187 (2019).

2. WHO. "WHO Guidelines on Safety Monitoring of Herbal Medicines in Pharmacovigilance Systems", Geneva, Switzerland, 2004, World Health Organization.

3. B. Goel and N. Maurya, "Memory booster herb (natural cognitive enhancers): An overview", Int J Physiol Nutr Phys Educ, 4 (1) 975 - 979, (2019).

4. J. Shi, X. Zou, J. Zhao, H. Mel, K. Wang, $X$. Wan and H. Chen, "Determination of total flavonoids content in fresh Ginkgo biloba leaf with different colors using near infrared 
spectroscopy", Spectrochim Acta A Mol

Biomol Spectrosc, 94, 271 - 276 (2012).

5. C. C. Chang, M. H. Yang, H. M. Wen and J. C. Chern, "Estimation of Total Flavonoid Content in Propolis by Two Complementary Colorimetric Methods", J Food Drug Anal, 10 (3), 178 - 182 (2002).

6. R. Lysiuk and N. Hudz, "Differential Spectrophotometry: Application for Quantification of Flavonoids in Herbal Drugs and Nutraceuticals", Int J Trends Food Nutr, 1, e102 (2017).

7. WHO, "WHO guidelines on good manufacturing practices (GMP) for herbal medicines", WHO Library, Switzerland, 2007, 92p.

8. K. Ražná, Z. Sawinska, E. Ivanišová, N. Vukovic, M. Terentjeva, M. Stričík and M. Kačániová, "Properties of Ginkgo biloba L.: Antioxidant Characterization, Antimicrobial Activities, and Genomic MicroRNA Based Marker Fingerprints", Int J Mol Sci., 21(9), 3087 (2020).

9. WHO, "Quality control methods for herbal materials", World Health Organization, Geneva, 2011.

10. United States Pharmacopoeia, USP 41NF36.

11. E. Pereira, L. Barros and I. C.F.R. Ferreira, "Chemical characterization of Ginkgo biloba L. and antioxidant properties of its extracts and dietary supplements".

Ind Crops Prod.,

51, 244-248(2013) .

12. G.C. Yen and C. Y. Hung," Effects of alkaline and heat treatment on antioxidative activity and total phenolics of extracts from Hsian-tsao (Mesona procumbens Hemsl.)", Food Res, 33, 487-492 (2013).

13. L. Rimkiene, A. Kubiliene, A. Zevzikovas, D. Kazlauskiene and V. Jakstas, "Variation in Flavonoid Composition and Radical-Scavenging Activity in Ginkgo biloba L. due to the Growth Location and Time of Harvest", Journal of Food Quality, 1 - 8 (2017).

14. B. Sun, D. L. Dilcher, D. J. Beerling, C. Zhang, D. Yan and E. Kowalski,
"Variation in Ginkgo biloba L. leaf characters across a climatic gradient in China", Proceedings of the National Academy of Sciences, 100(12), 71417146 (2013).

15. G. wang, F. Cao and Y. El-Kassaby, "Role of Temperature and Soil Moisture Conditions on Flavonoid Production and Biosynthesis-Related Genes in Ginkgo (Ginkgo biloba L.) Leaves". Nat Prod Chem Res, 3:1 (2015).

16. J. Kobus, E. Flaczyk, A. Siger, M. Nogala-KaÅ,ucka, J. A. Korczak and R.B. Pegg, "Phenolic compounds and antioxidant activity of extracts of Ginkgo leaves". Eur J Lipid Sci Technol., 111(11), 1150-1160 (2009).

17. I. D. Boateng and X.M. Yang, "Effect of different drying methods on product quality, bioactive and toxic components of Ginkgo biloba L. seed", J Sci Food Agric, 101, 3290 - 3297 (2021).

18. British Pharmacopeia, 2016, vol V, p206-210.

19. S. Ion, "The anatomic study of the Ginkgo biloba L. leaf", International Symposium on Agriculture, 2008, 4th, $5 \mathrm{p}$.

20. W. Kneifel, E. Czech and B. Kopp B, "microbial contamination of medicinal plants, A review", Planta Medica, 68(1), 5-15 (2002).

21. M. Ratajczak, D. Kaminska, A. Błaszkiewicz and J. Matysiak, "Quality of Dietary Supplements Containing Plant-Derived Ingredients Reconsidered by Microbial Approach", Int J Environ Res Public Health, 17, 6837 (2020).

22. A. Marcelo and B. Tais, "Microbial Quality of medicine plant material review", Latest Research (inti Quality Control, chapter 4,2012,p17.

23. C. C. A. do A Santos, E. G. de Almeida, G. V. P. de Melo and R. F. Schwan, "Microbial and physicochemical characterisation of caxiri, an alcoholic beverage produced by the indigenous Juruna people of Brazil". Int J Food Microbiol, 156 (2), $112-121$. 
24. A. Okunlola, A. Adewoyin and O. Odeku, " Evaluation of Pharmaceutical and Microbial Qualities of Some Herbal Medicinal Products in South Western Nigeria", Trop J Pharm Res, 6 (1), 661670 (2007).

25. A. Tournas, E. Katsoudas and E. Miracco, "Molds, yeasts and aerobic plate counts in ginseng supplements", Int J Food Microbiol, 108, 178 - 181 (2006) .
26. W. Tassaneeyakul, E. R . Fazeli, S. Pprasuphatana and J. Bohm, "Contamination of Aflatoxins in Herbal Medicinal Products in Thailand", Mycopathologia, 158, 239 - 244 (2004).

27. J.C. Brown and X. Jiang, Prevalence of antibiotic-resistant bacteria in herbal products, J Food Prot, 71, 1486 - 1490 (2008). 


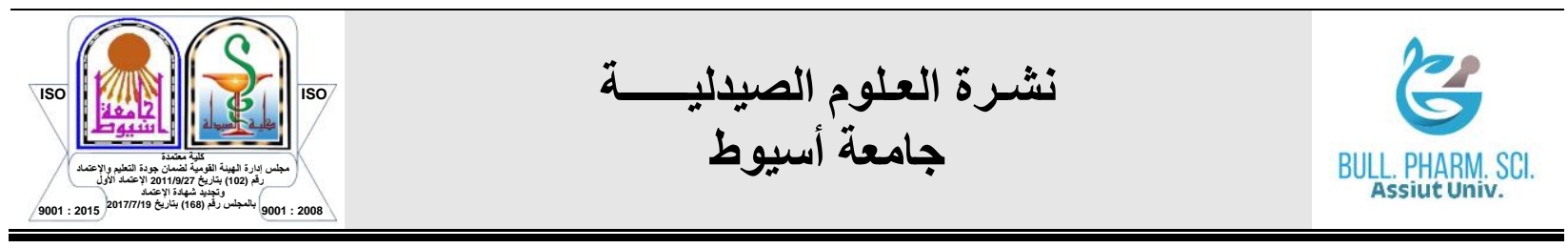

محتوى الفلافونويد الكلي ، التقيم المجهري والميكروبي لمنتجات الجنكوبيلوبا

$$
\text { نوار أحمد "* - هانى سالم ب - رامز رستمّ }
$$

' قسم مراقبة جودة الأدوية والكيمياء الصيدلية ، كلية الصيدلة ، جامعة البعث ، حمص ، سوريا

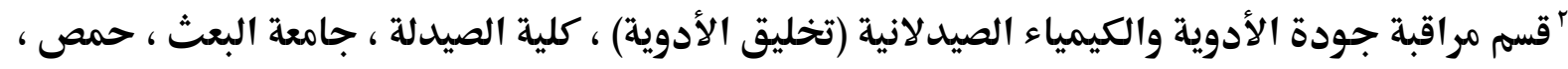

"قسم العلم الأدوية الإكلينيكي ، كلية الطب ، جامعة البعث ، حمص ، سوريا

يعد الجنكوبيلوبـا مـن المستحضـر ات العشبية واسـعة الاستخدام ، وكونـه مـن مصدر

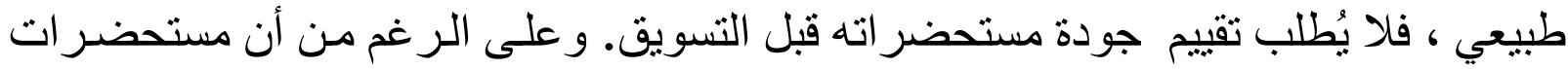

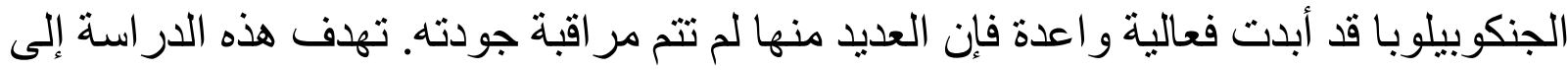

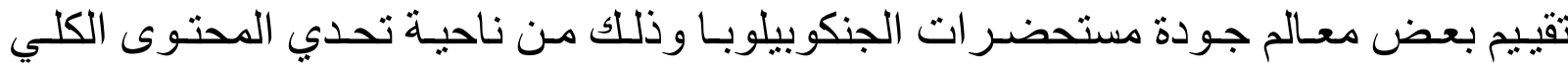

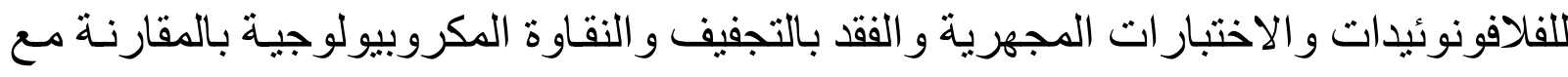

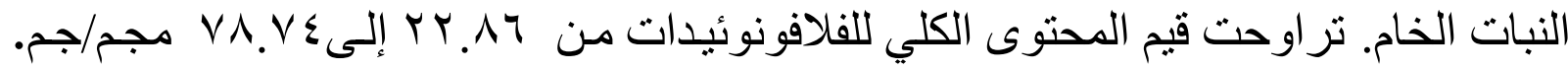

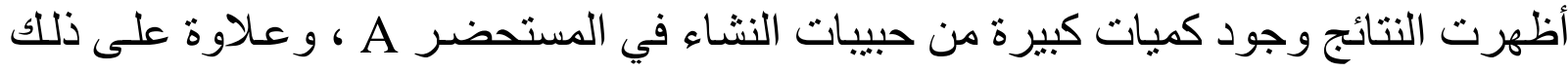

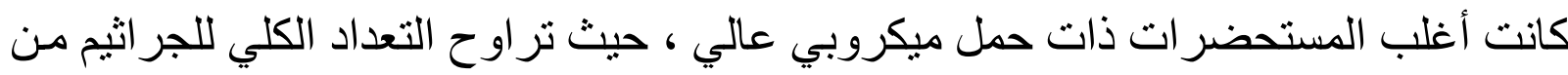

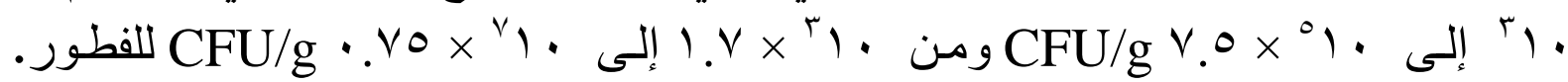

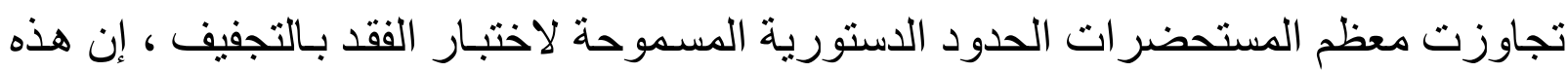
المعطيات قد تهدد صحة المستهلك. 